Check for updates

Cite this: RSC Adv., 2017, 7, 22610

\title{
Nitrogen-doped porous carbon derived from Fe- MIL nanocrystals as an electrocatalyst for efficient oxygen reduction
}

\author{
Limeng Yang, ${ }^{\text {ab }}$ Yangzhi Bai, ${ }^{\text {ab }}$ Hongjie Zhang, ${ }^{\text {ab }}$ Jiangtao Geng, ${ }^{a}$ Zhigang Shao (DD *a \\ and Baolian $\mathrm{Yi}^{\mathrm{a}}$
}

Exploring cheap and stable electrocatalysts to replace Pt for the oxygen reduction reaction (ORR) is now the key issue for the large-scale application of fuel cells. Herein, we report a novel mesoporous carbon material prepared by one-step pyrolysis of a dicyandiamide (DCD)-doped iron-based metal organic framework (MOF) compound-Materiaux de l'Institute Lavosier-101(Fe) (MIL-101(Fe)). The as-prepared nitrogen mesoporous carbon (MIL-5 DCD-800) is characterized by transmission electron microscopy (TEM), Xray powder diffraction (XRD), $\mathrm{N}_{2}$ sorption isotherms and $\mathrm{X}$-ray photoelectron spectroscopy. MIL-5 DCD800 shows an onset potential of $1.08 \mathrm{~V}$ (vs. RHE) and a half-wave potential of $0.86 \mathrm{~V}$ (vs. RHE) in $0.1 \mathrm{M}$ $\mathrm{KOH}$, which are similar to those of commercial Pt/C $\left(1.05 \mathrm{~V}(0.05 \mathrm{~mA} \mathrm{~cm})^{-2}\right)$. Furthermore, the electrocatalyst also possesses a much better stability and resistance to methanol crossover than $\mathrm{Pt} / \mathrm{C}$. This excellent performance is attributable to the presence of pyridinic- and graphitic- $\mathrm{N}$ together with abundant Fe active sites that promotes the four-electron process in the ORR. High pore volume and appropriate mesopores boost the mass transfer and reactivity during electrocatalysis.

Received 6th December 2016
Accepted 16th March 2017

DOI: $10.1039 / \mathrm{c} 6 \mathrm{ra} 27834 \mathrm{e}$

rsc.li/rsc-advances and durability ${ }^{8}$ of metal chalcogenides, more and more efforts have been made on metal $(\mathrm{M}-\mathrm{Nx} / \mathrm{C})$ and non-metal carbonsupported nitrogen $(\mathrm{Nx} / \mathrm{C})^{9-11}$ materials. In view of the point that catalyst's electrocatalytic activity results from the entrapment of metal sites, ${ }^{\mathbf{1 2 , 1 3}}$ pyrolyzed $\mathrm{M}-\mathrm{Nx} / \mathrm{C}$ materials are considered the most promising ORR catalysts, ${ }^{\mathbf{1 4}}$ especially $\mathrm{Fe}-\mathrm{Nx} / \mathrm{C}$ catalysts. $^{15-17}$ On the other hand, metal-organic frameworks (MOFs), thanks to their well-defined porous structures and regular arrangement of metal nodes and heteroatoms, are viewed as a brilliant precursor or template to synthesize new forms of $\mathrm{M}-\mathrm{Nx} / \mathrm{C}$ materials. ${ }^{18}$ One specific area in which MOF-derived heteroatom decorated carbon materials can play an important role is the catalysis of oxygen reduction reactions in fuel cells, especially as ZIFs ${ }^{19-21}$ and MILs ${ }^{22-24}$ among several MOF families. As Zi-Feng Ma et al. reported, ${ }^{25}$ a series of metal macrocycles showed decreasing catalytic activities towards the ORR in the order $\mathrm{Fe}>\mathrm{Co}>\mathrm{Zn}$. However, there aren't so many Fe containing ZIFs naturally. Accordingly, scientists often doped Fe source into other metal containing MOF precursors, such as $\mathrm{Zn}$ containing ZIF-7, ${ }^{26}$ ZIF-8 (ref. 27) and IRMOF-3. ${ }^{28}$ Yet, these synthetic methodologies are complex, expensive and time-consuming as they require the fabrication of sacrificial templates or $\mathrm{O}_{2}$-free environment besides the use of hazardous substances for template removal, which limits their competitiveness against Pt-based catalysts. As a result, the MIL family built from trivalent metal centers $\left(\mathrm{Fe}^{3+}\right.$ etc.) pioneered by Ferey and co-workers ${ }^{29}$ has recently attracted the attention of experts due to their enormous porosity, large pores and enhanced stability. ${ }^{30}$
${ }^{a}$ Dalian National Laboratories for Clean Energy (DNL), Dalian Institute of Chemical Physics (DICP), Chinese Academy of Sciences, 457 Zhongshan Road, Dalian 116023, China.E-mail: zhgshao@dicp.ac.cn

${ }^{b}$ University of Chinese Academy of Sciences, Beijing 100039, PR China 
Here, we prepared an excellent pyrolyzed $\mathrm{M}-\mathrm{Nx} / \mathrm{C}$ for the first time with a nitrogen-doped MIL-101(Fe) as precursor under $\mathrm{HF}$ and surfactant-free conditions in a round-bottom flask. To understand the influences of the nitrogen dopant amounts and pyrolysis temperature, we optimized the synthesis method and found out that MIL-5 DCD-800 catalyst behaved best among all the obtained catalysts. These unique properties are expected to significantly enhance the resulting fuel cell performance.

\section{Experimental}

\section{Material synthesis}

Material. $\mathrm{FeCl}_{3} \cdot 6 \mathrm{H}_{2} \mathrm{O}(\mathrm{AR})$ was purchased from Damao Chemical Reagent Co. (Tianjin, China) and 1,4-benzenedicarboxylic acid $\left(\mathrm{H}_{2} \mathrm{BDC}, \mathrm{AR}\right)$ was purchased from Kefeng Chemical Reagent Co. (Shanghai, China). Dicyandiamide (DCD, AR) were purchased from Guangfu Fine Chemical Engineering Institution. $N, N$-Dimethylformamide (DMF, AR) was purchased from Chemreagent Co. (Tianjin, China). Milli-Q UV-plus water $\left(18.2 \mathrm{M} \Omega \mathrm{cm}\right.$ ) from a Millipore water system (Synergy ${ }^{\circledR} \mathrm{UV}$, France) was used throughout the experiments.

Synthesis of Fe-MIL precursors. The Fe-MIL NPs were synthesized according to the previously reported hydrothermal method with slight modification. Briefly, iron(III)chloridehexahydrate (1.084 mg, $4 \mathrm{mmol})$, 1,4-benzenedicarboxylic acid ( $\mathrm{H}_{2} \mathrm{BDC}, 0.664 \mathrm{~g}, 4 \mathrm{mmol}$ ) and $\mathrm{N}, \mathrm{N}$-dimethylformamide (DMF, $197 \mathrm{~mL}, 2.54 \mathrm{~mol}$ ) were mixed in a $250 \mathrm{~mL}$ flask by magnetic stirring for $5 \mathrm{~min}$ at room temperature to form a solution with a $\mathrm{Fe}^{3+} / \mathrm{H}_{2} \mathrm{BDC} / \mathrm{DMF}$ molar ratio of $1: 1: 635$. This solution was then degassed by shaking in an ultrasonic bath for $10 \mathrm{~min}$ in order to remove air bubbles and then the vial was sealed and heated to $150{ }^{\circ} \mathrm{C}$ for $12 \mathrm{~h}$ under stirring. Then, the hot solution was poured out without cooling and products were isolated immediately by centrifugation. The basal brown precipitate was washed thoroughly with DMF and dried under vacuum overnight, the final product was denoted as MIL-101(Fe).

Preparation of N-doped carbon nanomaterials. The Fe-MIL powder was dispersed in ethanol solution containing proper quantity of DCD $\left(0.03125 \mathrm{~g} \mathrm{~mL}^{-1}\right)$ for $4 \mathrm{~h}$ under magnetic stirring at $80{ }^{\circ} \mathrm{C}$, and then the alcohol solvent was removed in atmosphere. Next, the obtained pink powder products were ground and denoted as MIL- $x$ DCD, where $x$ refers to the mass ratio of DCD to Fe-MIL. Then, the calcination procedures of MIL- $x$ DCD were conducted in a flow of ultrapure Ar and kept for 2 hours under different temperature with the heating rate of $5{ }^{\circ} \mathrm{C} \min ^{-1}$. The pyrolyzed samples (i.e. the electrocatalysts) were denoted as MIL- $x$ DCD- $y$, where $y$ refers to the pyrolysis temperature of MIL- $x$ DCD. Last, the black powder was ground for the electrocatalyst characterization.

\section{Physical characterization}

The field-emission scanning electron microscopy (FESEM) was performed on JEOL JSM-6360 scanning electron microscope operating at an acceleration voltage of $1.50 \mathrm{kV}$. The MIL-101(Fe) precursor sample was sprayed by gold atoms to enhance its electrical conductivity. Transmission electron microscopy (TEM) was conducted on JEM-2100 operating at $200 \mathrm{kV}$.

Powder X-ray diffraction (XRD) patterns were collected on a D/MAX2500VB2/PC with a $2 \theta$ range of $5-90^{\circ}$ and a scan speed of $5^{\circ} \mathrm{min}^{-1}$ at ambient temperature. X-ray photoelectron spectroscopy (XPS) was carried out on a Thermo Scientific ESCA Lab250 Xi spectrometer. The metal content of electrocatalysts was determined by PerkinElmer 7300DV inductively coupled plasma atomic emission spectrometry (ICP-OES).

Nitrogen sorption measurements at $77 \mathrm{~K}$ were carried out by using a Quantachrome Autosorb-IQ gas adsorption analyzer. The samples were degassed at $90{ }^{\circ} \mathrm{C}$ for $2 \mathrm{~h}$ and $200{ }^{\circ} \mathrm{C}$ for $5 \mathrm{~h}$ under dynamic vacuum before tests. The resulting BET surface areas were calculated from the adsorption branches and the pore size distributions were fitted from Quenched Solid Density Functional Theory (QSDFT) method.

\section{Electrochemical measurements}

Electrochemical measurements were performed using a $\mathrm{CHI}$ Electrochemical Station (Model 730D) in a three-electrode electrochemical cell at room temperature. Platinum foil and an $\mathrm{Ag} / \mathrm{AgCl}$ electrode were using as the counter and reference electrode, respectively. The catalyst layer on the glassy carbon electrode $\left(0.1256 \mathrm{~cm}^{2}\right)$ was prepared as follows. The Fecontained MIL- $x$ DCD- $y$ powder were dissolved in a mixture of water, isopropyl alcohol and Nafion (5.0 wt\%, Du Pont Corp.) with a ratio of $1: 9: 0.1(\mathrm{v} / \mathrm{v} / \mathrm{v})$ under sonication to get $2 \mathrm{mg}$ $\mathrm{mL}^{-1}$ ink. Next the uniformly dispersed ink was dropped onto the glassy carbon disk, which was then left to dry in air at room temperature, to yield a catalyst loading of ca. $400 \mu \mathrm{g} \mathrm{cm} \mathrm{cm}^{-2}$. Comparatively, the loading of commercial Pt/C (20 wt\%, Johnson Matthey Co., Ltd) catalyst was controlled at $20 \mu \mathrm{g}_{\mathrm{Pt}} \mathrm{cm}^{-2}$. All the potentials reported in this work were expressed versus the reversible hydrogen electrode (RHE) based on the standard calculation method: in $0.1 \mathrm{M} \mathrm{KOH}$ solution $(\mathrm{pH}=13), E(\mathrm{RHE})=$ $E(\mathrm{Ag} / \mathrm{AgCl})+0.965$.

The cyclic voltammetry (CV) curves were obtained by cycling scan at room temperature after purging $\mathrm{N}_{2}$ or $\mathrm{O}_{2}$ for at least $20 \mathrm{~min}$. The electrode was subjected to electrochemical treatment by potential cycling between 0.05 and $1.2 \mathrm{~V}$ at $100 \mathrm{mV} \mathrm{s}^{-1}$ in $0.1 \mathrm{M} \mathrm{KOH}$ until stable voltammogram curves were obtained.

In rotating disk electrode (RDE) tests, the background capacitive currents were recorded in a potential range from 1.2 to $0.2 \mathrm{~V}$ in nitrogen-saturated electrolyte at a scan rate of $10 \mathrm{mV}$ $\mathrm{s}^{-1}$. Then linear sweep voltammograms (LSV) in oxygensaturated electrolyte were measured at an electrode rotation speed of $1600 \mathrm{rpm}$. The oxygen reduction current was corrected by the background current.

In rotating ring-disk electrode (RRDE, PINE AFE7R9GCPT) tests, the ring potential was set to $1.466 \mathrm{~V}$ to oxidize the hydrogen peroxide produced during oxygen reduction on the disk electrode. The number of electron transferred $(n)$ during ORR and the hydrogen peroxide yield $\left(\% \mathrm{H}_{2} \mathrm{O}_{2}\right)$ were calculated using the following equations:

$$
\% \mathrm{H}_{2} \mathrm{O}_{2}=\frac{200 I_{\mathrm{r}}}{N\left|I_{\mathrm{d}}\right|+I_{\mathrm{r}}} \times 100 \%
$$




$$
n=4-2 \times \frac{\% \mathrm{H}_{2} \mathrm{O}_{2}}{100}
$$

where $N$ is the collection efficiency, which is 0.37 , the $I_{\mathrm{r}}$ and $I_{\mathrm{d}}$ are the ring current and disk current, respectively.

Koutecky-Levich plots were obtained on the basis of RDE tests at different rotating rates and the electron transfer number during ORR process can be determined from the slopes of Koutecky-Levich plots by the following equation:

$$
j_{\lim }=0.62 n F D_{\mathrm{O}_{2}}{ }^{\frac{2}{3}} \nu^{\frac{-1}{6}} C_{\mathrm{O}_{2}} \omega^{\frac{1}{2}}
$$

where $j_{\text {lim }}$ is the limiting current density; $n$ is the number of electrons transferred per oxygen molecule; $F\left(96485 \mathrm{C} \mathrm{mol}^{-1}\right)$ is the Faraday constant; $D_{\mathrm{O}_{2}}\left(1.9 \times 10^{-5} \mathrm{~cm}^{2} \mathrm{~s}^{-1}\right)$ is the diffusion coefficient of $\mathrm{O}_{2}$ in $0.1 \mathrm{KOH}$ and $C_{\mathrm{O}_{2}}\left(1.2 \times 10^{-6} \mathrm{~mol} \mathrm{~cm}{ }^{-3}\right)$ is the concentration of $\mathrm{O}_{2}$ in the electrolyte; $\nu$ is the kinetic viscosity of the solution $\left(0.01 \mathrm{~cm}^{2} \mathrm{~s}^{-1}\right)$; and $\omega$ is the electrode rotation rate $\left(\mathrm{rad} \mathrm{s}^{-1}\right)$.

As for accelerated durability test (ADT), the electrodes were cycled between 0.6 and $1.0 \mathrm{~V}$ for a whole number of 2000 cycles in $\mathrm{O}_{2}$ saturated $\mathrm{KOH}(0.1 \mathrm{M})$ with a scan rate of $100 \mathrm{mV} \mathrm{s}^{-1}$. Simultaneously, CV curves and ORR polarization curves were collected in aqueous $\mathrm{KOH}$ solution at certain cycles to record the degradation of home-made electrocatalysts and commercial $\mathrm{Pt} / \mathrm{C}$.

\section{Results and discussion}

\section{Materials characterization}

Fig. 1b shows the wide angle XRD patterns of heat-treated samples doped different DCD. Most of the heat-treated samples doped DCD give a series of peaks at $44.6^{\circ}, 65.1^{\circ}$ and $82.5^{\circ}$, which are attributed to metallic iron [Joint Committee on Powder Diffraction Standards (JCPDS) number 01-087-0722]. It's obvious that the amount of Fe generally increases when the heat-treat temperature arises except for MIL-5 DCD-900. Besides, there are few iron oxides (JCPDS number 00-025-1402) existing in doped samples which are mainly contained in undoped with peaks at $30.3^{\circ}, 35.7^{\circ}$ and $57.4^{\circ}$. When the pyrolysis temperature rises to $800{ }^{\circ} \mathrm{C}, \mathrm{Fe}_{3} \mathrm{C}$ (JCPDS number 00-003-0411) is detected in MIL-5 DCD-y with peak of $26.2^{\circ}$. Furthermore, there are also weak $\mathrm{Fe}_{3} \mathrm{~N}$ (JCPDS number $00-001-1236)$ peaks at $43.3^{\circ}$ indicating the lower
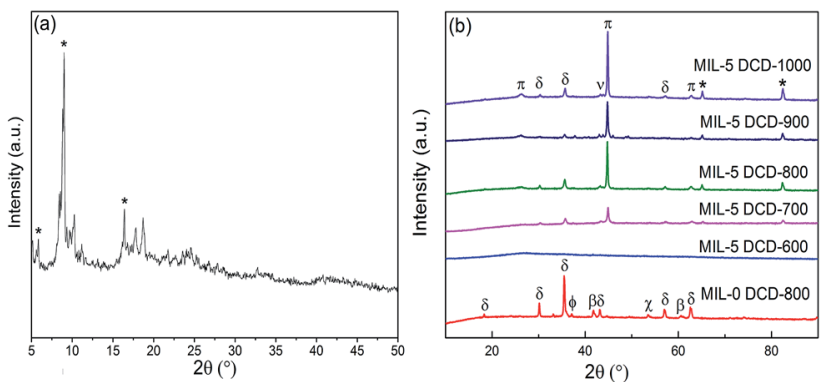

Fig. 1 XRD patterns: (a) MIL-101(Fe); and (b) MIL-5 DCD-y (* Fe; $\delta \mathrm{Fe}_{2} \mathrm{O}_{3} ; \pi \mathrm{Fe}_{3} \mathrm{C} ; v \mathrm{Fe}_{3} \mathrm{~N} ; \beta \mathrm{FeO} ; \chi$ carbon; $\phi \mathrm{Fe}_{3} \mathrm{O}_{4}$ ).
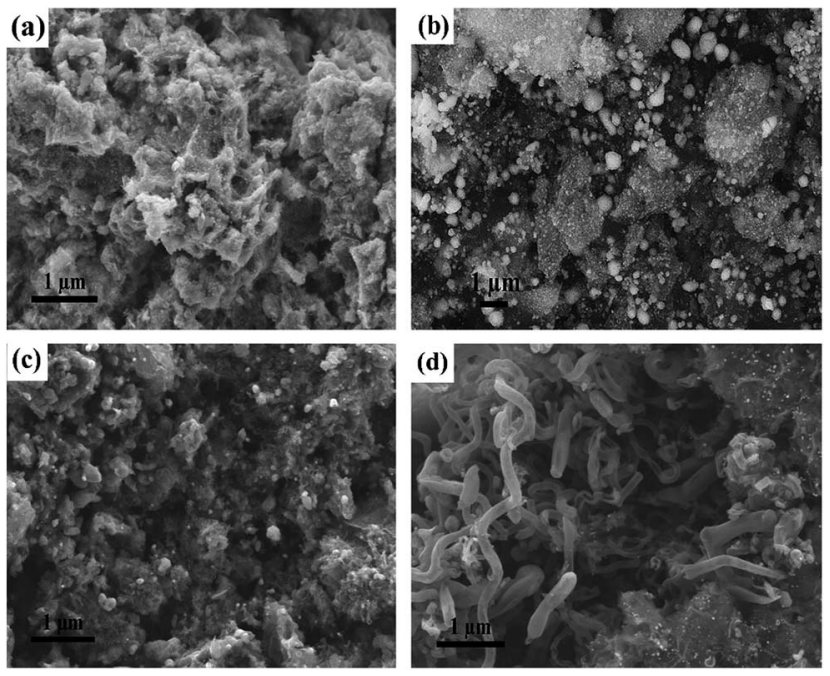

Fig. 2 FESEM image of the MIL-5 DCD-700 (a), MIL-5 DCD-800 (b), MIL-5 DCD-900 (c) and MIL-5 DCD-1000 catalyst (d).

crystallinity of $\mathrm{Fe}_{3} \mathrm{~N}$ in MIL-5 DCD-y. Without doping $\mathrm{N}$, only displayed $\mathrm{FeO}$ (JCPDS number 01-089-0687), $\mathrm{Fe}_{3} \mathrm{O}_{4}$ (JCPDS number 03-065-3107) and carbon (JCPDS number 00-0501084) besides $\mathrm{Fe}_{2} \mathrm{O}_{3}$. The mean diameter of $\mathrm{Fe}$ particles of MIL-5 DCD-(700-900) calculated from Scherrer equation is $60.5 \mathrm{~nm}$ and the MIL-5 DCD-1000 is $47.7 \mathrm{~nm}$. It seemed that the mean diameter of Fe particles calculated through XRD patterns were not completely in accordance with the SEM photos of MIL-5 DCD-700 and MIL-5 DCD-1000 catalysts in Fig. 2. It may be the reason that the mean diameter of $\mathrm{Fe}$ particles of MIL-5 DCD-700 and MIL-5 DCD-1000 are smaller than $50 \mathrm{~nm}$ resulting that Scherrer equation isn't applicative anymore. In addition, the mean diameter doesn't seem to increase with the pyrolysis temperature when it turns to $1000{ }^{\circ} \mathrm{C}$. It may be that the generated carbon nanotubes prohibited the aggregation of Fe particles under the high temperature of $1000{ }^{\circ} \mathrm{C}$ in Fig. $2 \mathrm{~d}$.

To further explore the morphology and crystalline information of best-performance MIL-5 DCD-800 catalyst, it was characterized by high-resolution transmission electron microscopy (HRTEM) and selected area electron diffraction (SAED). The TEM morphology of MIL-5 DCD-800 catalyst in Fig. 3a can show that it's composed of small graphene-wrapped nanoparticles and large agglomerated metal composites. In view of the XRD results in Fig. 1b, the nanoparticles embedded in carbon matrix and several hundreds of nanometer-size dark particles could most possibly be $\mathrm{Fe}$ or $\mathrm{Fe}_{2} \mathrm{O}_{3}$. While as seen in Fig. $3 \mathrm{~b}$, the $10 \mathrm{~nm}$-diameter small nanoparticles are Fe particles. Because it can be measured that the lattice spacing is about $0.207 \mathrm{~nm}$, which is slightly larger than the standard value of $0.204 \mathrm{~nm}$, corresponding to the [110] plane of metallic Fe. The larger lattice space might be ascribed to the spaces of iron with intercalated nitrogen atom, which accordingly enlarges the lattice constant. ${ }^{31}$ As for the large agglomerating metal composites, we observed polycrystal lattice in Fig. 3c. The lattice spacing is about $0.309 \pm 0.006 \mathrm{~nm}$ nanoparticles which 

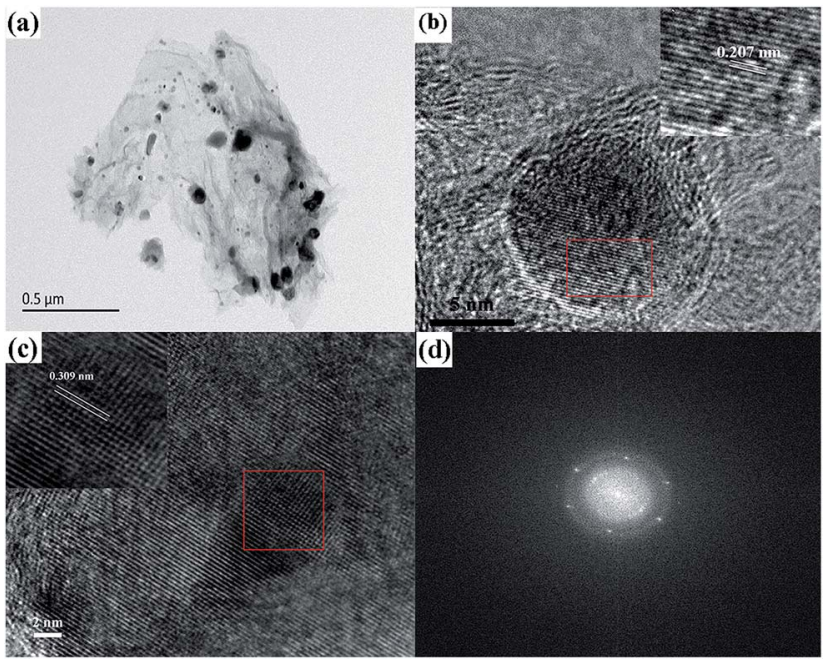

Fig. 3 TEM image of the MIL-5 DCD-800 catalyst (a); HRTEM images of the MIL-5 DCD-800 catalyst (b and c); SAED image of the MIL-5 DCD -800 catalyst (d).

corresponds to the [111] plane of $\mathrm{Fe}_{3} \mathrm{C}$. Particularly, the SAED pattern (in Fig. 2d) of the nanoparticle also reveals that the large irregular particles are polycrystalline. The formation of carbon layer around $\mathrm{Fe}_{3} \mathrm{C}$ likely results from the carbonization catalytic effect of Fe during the pyrolysis process. In addition, we observed other tiny carbon-wrapped nanoparticles with a lattice spacing of $0.466 \mathrm{~nm}$ which corresponding to the [002] plane of the $\mathrm{Fe}_{2} \mathrm{O}_{3}$. To understand the morphology and the microstructure of this materials, more SEM photographs of MIL-5 DCD-700, MIL-5 DCD-800, MIL-5 DCD-900 and MIL-5 DCD-1000 are given in Fig. 2. The morphology of MIL-5 DCD800 is similar to MIL-5 DCD-900 with aggregated several hundreds of nanometer-size metal particles and carbon bulks. There are obvious carbon nanotubes generated in MIL-5 DCD-1000 ascribed to high pyrolysis temperature while MIL-5 DCD-700 seems like abundant tiny metal species embedded in amorphous carbon.

As a subclass of MOFs, MIL-101(Fe) consists of 1,4-benzenedicarboxylic acid as organic ligands and $\mathrm{Fe}$ ions as metal centers whose inorganic secondary building unit (SBU) is composed of a carboxylate-bridged, oxo-centered, trinuclear $\mathrm{Fe}^{3+}$ complex. ${ }^{32}$ As for the definition of MIL-101(Fe), the crystal topology of MIL-101(Fe) precursor appears a rigid zeotype octahedral structure with a length of 200-300 $\mathrm{nm}$ in Fig. $4 \mathrm{a}$ and $\mathrm{b}$ which is corresponding with the reference reported. ${ }^{33}$ Moreover, the structures of obtained MIL-101(Fe) precursor characterized by XRD shows that the synthesized precursor is exactly MIL-101(Fe) crystal according to the peaks reported in the literature. ${ }^{23}$ However, compared with MIL101(Fe), MIL-5 DCD-800 catalyst did not preserve the original shape of the precursor crystal as shown in Fig. $4 \mathrm{a}$ and $\mathrm{b}$. The topology and textural property's modification of MIL-5 DCD-800 catalyst may result from the structure collapse of MIL-101(Fe) precursor, the polymerization and decomposition of nitrogen source DCD and the conversion of iron-based intermediates.

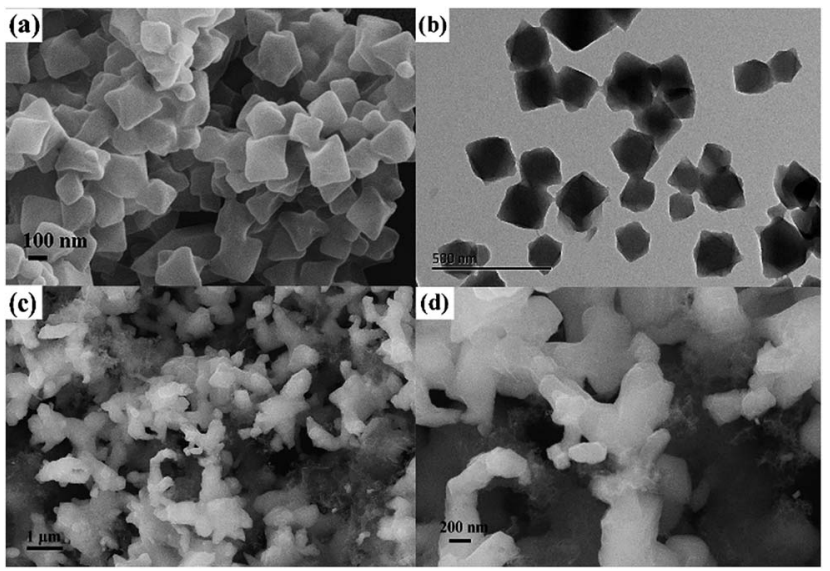

Fig. 4 FESEM image of the MIL-101(Fe) precursor ( $a$ and $b$ ) and MIL0 DCD-800 catalyst (c and d).

The detail textural property and inner structure of MIL precursor and electrocatalyst samples can be illustrated by $\mathrm{N}_{2}$ sorption isotherms and pore size distribution analysis. For instance, MIL-101(Fe) produced a type-I isotherm indicating a microporous structure (Fig. 5a), with a large BET surface area of $1474.596 \mathrm{~m}^{2} \mathrm{~g}^{-1}$ (Table 1). The BET surface area together with the XRD pattern in Fig. 1a proves it's undoubtedly MIL-101(Fe). It's mainly attributed to the micropores taking up about $31.48 \%$ of the total pore volume. The tiny surface area of catalyst rarely demonstrated any pore structure. Looking at the FESEM image of in Fig. $4 c$ and d, we can observed a little bit shape of the original octahedral framework of MIL-101(Fe) precursor and the poor surface area of may result from the agglomeration of particles. From the BET surface area of different samples in Table 1 , we can easily discovery that the BET surface area of electrocatalysts also dramatically decreased after calcination especially when DCD wasn't doped. On the other hand, MIL-5 DCD-800 possesses the largest BET surface area between the MIL-5 DCD-y catalysts and its total pore volume decreased around only $3.5 \%$ of MIL precursor's total pore volume. It demonstrated that the complement of nitrogen source can prohibit the structure collapse of MIL-101(Fe) precursor to some extent. The obvious hysteresis loop and vertical tail of MIL-5 DCD-800 and MIL-5 DCD-700/900/1000 catalyst revealed
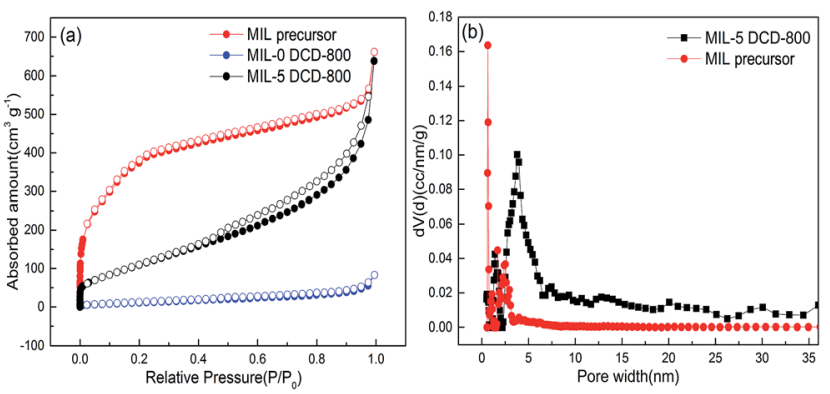

Fig. 5 Porous texture analysis of electrocatalysts: (a) $N_{2}$ sorption isotherms at $77 \mathrm{~K}$ (closed, adsorption; open, desorption); (b) NLDFT (non-local density functional theory) pore size distribution. 
Table 1 The surface area and pore volume of different samples

\begin{tabular}{lcll}
\hline Catalyst & $\begin{array}{l}\text { BET surface } \\
\text { area }\left(\mathrm{m}^{2} \mathrm{~g}^{-1}\right)\end{array}$ & $\begin{array}{l}\text { Micropore } \\
\text { volume }\left(\mathrm{cm}^{3} \mathrm{~g}^{-1}\right)\end{array}$ & $\begin{array}{l}\text { Total pore } \\
\text { volume }\left(\mathrm{cm}^{3} \mathrm{~g}^{-1}\right)\end{array}$ \\
\hline MIL precursor & 1474.60 & 0.473 & 1.023 \\
MIL-0 DCD-800 & 50.68 & - & - \\
MIL-5 DCD-600 & 113.04 & - & 0.222 \\
MIL-5 DCD-700 & 411.08 & - & 0.958 \\
MIL-5 DCD-800 & 452.33 & - & 0.987 \\
MIL-5 DCD-900 & 425.09 & - & 0.968 \\
MIL-5 DCD-1000 & 350.03 & - & 1.029
\end{tabular}

a typical type $\mathrm{H}_{3}$ isotherm which proved the presence of a certain portion of slit meso- and macro-pores (Fig. 5a). The pore-size distribution of MIL-5 DCD-800 was analyzed by NLDFT method for both micropores $(0-2 \mathrm{~nm})$ and mesopores $(2-50 \mathrm{~nm})$ although there aren't any micropores shown by $t$-plot method (Table 1).

In Fig. 5b, some $0.642 \mathrm{~nm}$-wide micropores in MIL precursor turned into $3.974 \mathrm{~nm}$-wide mesopores in MIL-5 DCD-800 during pyrolysis possibly because of the pore-forming effect of undecomposed carbonitride precursor.

The element compositions (at\%) and electronic states of $\mathrm{N} 1 \mathrm{~s}$ and Fe $2 \mathrm{p}$ in the surface layers of the MIL-5 DCD- $y$ catalysts pyrolyzed at different temperature were determined by XPS analysis (Fig. 6). The N 1s XPS spectra of the MIL-5 DCD-600 materials (Fig. 6a, c, e, g and i) can be deconvoluted into four types according to the binding energy: pyridine (398.7 eV), pyrrolic $(400.4 \mathrm{eV})$, graphitic $(401.3 \mathrm{eV})$ and oxidized $(403.8 \mathrm{eV})$ nitrogen species, ${ }^{21}$ respectively. It can be seen in Table 2 and Fig. 6 that the pyridinic N contributions of all MIL-5 DCD-y catalysts decreased with the increasing pyrolysis temperature while graphitic $\mathrm{N}$ fraction increased with temperature which is in accordance with other similar references. ${ }^{34,35}$ Through the ages, identifying the active sites of nitrogen-doped carbon materials for the ORR is under debate. Currently, the debate mainly focuses on whether the active sites are created by pyridinic $\mathrm{N}$ or graphitic $\mathrm{N}$. Pyridinic-N has long been proposed as the active site to promote the four-electron process in ORR. ${ }^{36-40}$ Recently, Nakamura et al. pointed that the carbon atoms adjacent to pyridinic-N with Lewis basicity were ORR active sites. ${ }^{41}$ Whatever, graphitic $\mathrm{N}$ atoms have been reported both experimentally and theoretically to serve as ORR catalytic sites due to their reduced adsorption energy. ${ }^{42}$ Kim et al. ${ }^{43}$ proposed that graphene edge structures after introduction of graphitic $\mathrm{N}$ not only enhanced the first electron transfer rate, but also showed preference for the in particular $4 \mathrm{e}^{-}$reduction pathway. Lai et $a .^{44}$ also found that the electrocatalytic activity of the $\mathrm{N}$ doped graphene catalyst mainly depended on the graphitic $\mathrm{N}$ content, which determined the limiting current density, while the pyridinic $\mathrm{N}$ species may have converted the ORR reaction mechanism from a $2 \mathrm{e}^{-}$dominated process to a $4 \mathrm{e}^{-}$dominated process and improved the ORR onset potential. As shown in Table 2, MIL-5 DCD-800 catalyst preserves the highest amount of pyridinic and graphitic $\mathrm{N}$ than other catalysts which may signpost a better performance. The binding energies between 705 and $730 \mathrm{eV}$ were assigned to Fe $2 \mathrm{p}$ peak deconvolution. It is
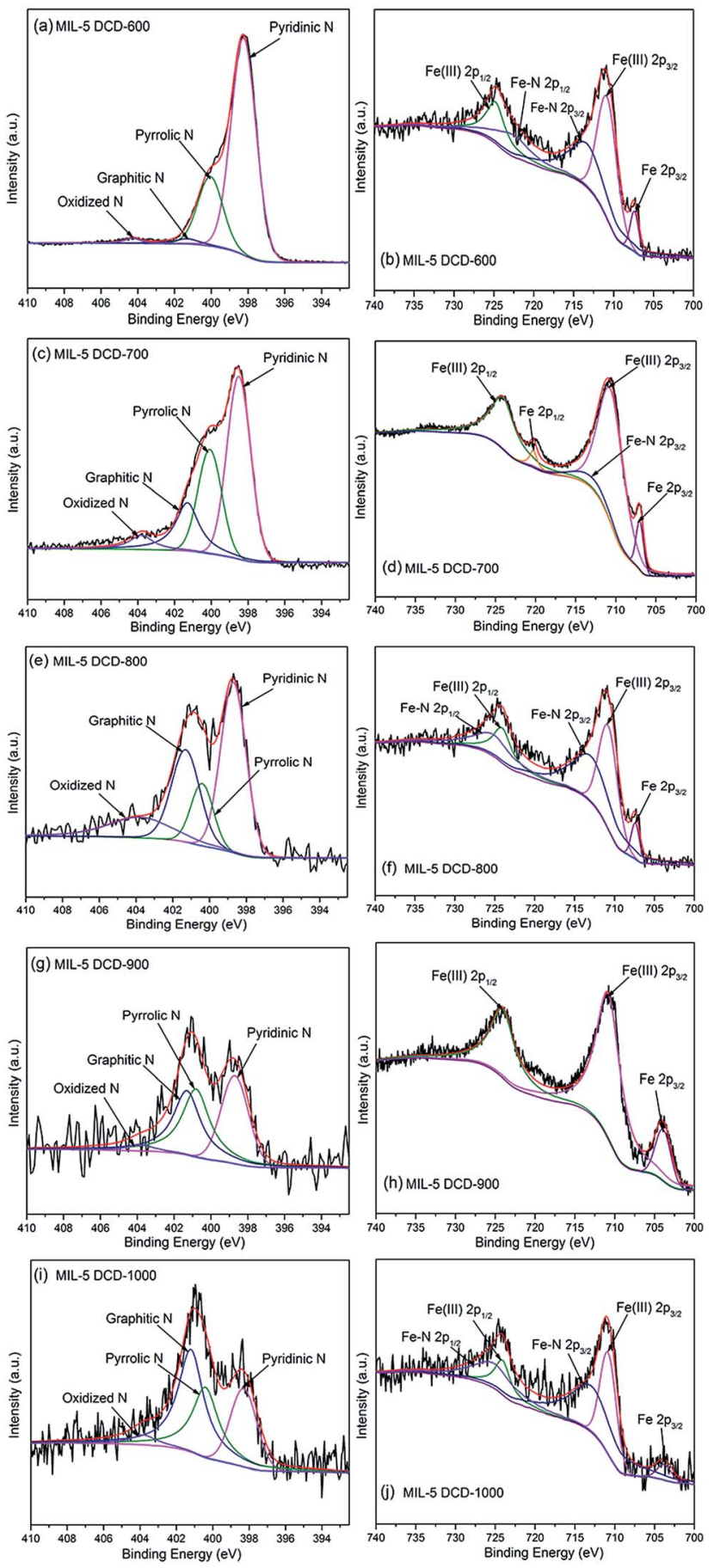

Fig. 6 High-resolution XPS spectra of $N$ 1s and Fe $2 p$ in the MIL-5 DCD-600 ( $a$ and b), MIL-5 DCD-700 (c and d), MIL-5 DCD-800 (e and f), MIL-5 DCD-900 (g and h), MIL-5 DCD-1000 (i and j) catalyst.

shown in the XPS Fe 2p spectrum of MIL-5 DCD-800 that the peaks centered at 710.8 and $724.3 \mathrm{eV}$ represent $\mathrm{Fe}(\mathrm{III}) 2 \mathrm{p}_{3 / 2}$ and $2 \mathrm{p}_{1 / 2}$, respectively, and no Fe(II) peak is observed (i.e. $709.6 \mathrm{eV}$ for $\mathrm{Fe}(\mathrm{II})) .{ }^{45}$ In addition, the trivial peak at $706.7-707.2 \mathrm{eV}$ may be representative of metal $\mathrm{Fe} 2 \mathrm{p}_{3 / 2}$ while the hump observed at $705 \mathrm{eV}$ for the MIL-5 DCD-800/900 sample is related to several of the metallic aggregates. ${ }^{27}$ As for $\mathrm{Fe}-\mathrm{N}$ bonding the peak is generally around $c a .713$ and $725 \mathrm{eV}^{45} \mathrm{Fe}$ is most likely 
Table 2 The nitrogen contents and states of MIL-5 DCD-y catalysts

\begin{tabular}{llllll}
\hline $\begin{array}{l}\text { Types of N } \\
\text { (at\%) }\end{array}$ & Pyridinic & Graphitic & Oxidized & Pyrrolic & $\begin{array}{l}\text { Pyridinic }+ \\
\text { graphitic }\end{array}$ \\
\hline MIL-5 DCD-600 & 51.9 & 11.0 & 11.0 & 24.5 & 62.9 \\
MIL-5 DCD-700 & 43.3 & 18.5 & 10.0 & 28.1 & 61.8 \\
MIL-5 DCD-800 & 35.9 & 27.5 & 18.0 & 18.6 & 63.4 \\
MIL-5 DCD-900 & 28.8 & 28.9 & 13.2 & 29.1 & 57.7 \\
MIL-5 DCD-1000 & 24.1 & 36.4 & 12.7 & 26.9 & 60.5 \\
& & & & &
\end{tabular}

complexed with $\mathrm{N}$ functions such as pyrrolic- $\mathrm{N}$ and pyridinic- $\mathrm{N}$ in MIL-5 DCD-y samples.

Moreover, the Fe contents in MIL-101(Fe) precursor, MIL0 DCD-800 and MIL-5 DCD-y catalyst characterized by ICPOES in Table 3 are more than the results of XPS in Table 4 . Probably because XPS data usually gives the surface composition rather than the bulk composition of ICP-OES results. Besides, the reason why Fe contents from XPS data of MIL-5 DCD-600 to MIL-5 DCD-900 catalyst decreased as the pyrolysis temperature increased may be that the surface graphene/CNT is thicker than $2 \mathrm{~nm}$ in MIL-5 DCD- $y$ as the pyrolysis temperature increased thus the wrapped iron nanoparticles inside cannot be detected by XPS (Fig. 2). It is evident that $\gamma-\mathrm{Fe}_{2} \mathrm{O}_{3}, \mathrm{Fe}_{3} \mathrm{~N}$ and metal $\mathrm{Fe}$ are the iron resource in MIL-5 DCD-800, from both XRD and XPS observations. The particles observed in the TEM images of MIL-5 DCD-800 should more likely be Fe oxides or metal iron since rarely no Fe carbides signal was shown in the XPS.

\section{Electrocatalytic activity}

To evaluate the influence of pyrolysis temperature and nitrogen dopant amounts, we investigated electrocatalysts with different nitrogen dopant amounts ${ }^{46}$ pyrolyzed from $600{ }^{\circ} \mathrm{C}$ to $1000{ }^{\circ} \mathrm{C}$. Fig. 7a shows the RDE polarization curve of the electrocatalysts prepared by pyrolysis of MIL-10 DCD from 600 to $1000^{\circ} \mathrm{C}$. With the increase of pyrolysis temperature, it seems that the electrochemical performance of different nitrogen dopant amounts catalysts reached their highest point at $800{ }^{\circ} \mathrm{C}$ in terms of onset potential and half-wave potential toward ORR separately (Fig. 7b). Moreover, different MIL- $x$ DCD-800 catalysts were compared in Fig. $7 \mathrm{c}$ and the MIL-5 DCD-800 catalyst exhibits the highest performance among other electrocatalysts with an ORR half-wave potential of $0.86 \mathrm{~V}$ and a limiting current density of $5.7 \mathrm{~mA} \mathrm{~cm}^{-2}$ which is about the same as commercial $20 \mathrm{wt} \% \mathrm{Pt} /$ C. The kinetic current density at $0.8 \mathrm{~V}$ is $22.0 \mathrm{~mA} \mathrm{~cm}^{-2}$ and the resulting mass activity is $55.1 \mathrm{~A} \mathrm{~g}^{-1}$. It may be the dominating presence of rich pyridinic- and graphitic- $\mathrm{N}$ and abundant carbon-wrapped metal Fe active sites in MIL-5 DCD-800 that
Table 4 Elemental compositions (in atom\%) of MIL-5 DCD-y catalysts

\begin{tabular}{llrl}
\hline Elements (at\%) & C & $\mathrm{N}$ & $\mathrm{Fe}$ \\
\hline MIL-5 DCD-600 & 57.67 & 36.89 & 5.43 \\
MIL-5 DCD-700 & 83.90 & 12.06 & 4.04 \\
MIL-5 DCD-800 & 91.69 & 5.69 & 2.62 \\
MIL-5 DCD-900 & 94.36 & 4.06 & 1.58 \\
MIL-5 DCD-1000 & 96.55 & 1.86 & 1.59
\end{tabular}

promote the four-electron process in ORR, leading to a better performance than the amino-MIL-53(Al) electrocatalyst made by Yao et al. ${ }^{22}$ directly pyrolyzed the naturally-nitrogen-contained MOF. As seen in Fig. 7d, the ORR capacity of MIL-5 DCD-800 which reserves most metal Fe active sites is no wonder superior than MIL-5 DCD-y with other pyrolysis temperature (Table 3). Fig. 7c and d shows the ORR polarization curves of MIL-101Fe precursor, MIL-0 DCD-800 and MIL-5 DCD-800. It's obvious that the nitrogen dopant and pyrolysis treatment are vital to the improvement of ORR electrocatalytical performance. Although the MIL-5 DCD-600 catalyst contains the similar highest content of pyridinic- and graphitic-N with MIL-5 DCD-800 catalyst (Table 2), it displays poor ORR catalytic activity. The main reason probably is the low surface area of MIL-5 DCD-600 (Table 1) in terms of other MIL-5 DCD-y catalyst. In addition, the detailed Fe coordinates of the best-performance MIL-5 DCD-800 catalyst should be further studied to investigate how they are coordinate with doped $\mathrm{N}$ atoms by characterizations such as Mössbauer spectroscopy, EXAFS. On the other hand, that some $0.642 \mathrm{~nm}$-wide micropores (Fig. $5 \mathrm{~b}$ ) in MIL precursor turned into $3.974 \mathrm{~nm}$-wide mesopores of MIL-5 DCD-800 during pyrolysis supported the opinion that large pore size of catalysts can facilitate the accessibility of reactant for ORR in fuel-cell test. ${ }^{47}$ It may be the fact that mesoporous frameworks serve as reactant buffering reservoirs while microporous textures only ensure a large surface area favorable to the exposure of active sites. Since in the fuel-cell test, the micropores supporting more active sites can hardly touch reactant molecules without the macro/mesopores of electrocatalyst facilitating the accessibility of reactant for ORR. Furthermore, the large BET surface area of MIL-5 DCD-800 also contributes to support of active sites leading to an enhanced catalytic activity.

The polarization curves obtained at different rotation speeds from RDE experiments are shown in Fig. 7e for MIL-5 DCD-800. The numbers of electrons transferred per $\mathrm{O}_{2}$ molecule were estimated using Koutecky-Levich (K-L) equation. As shown in Fig. 7f, the corresponding K-L plots show a good linearity and the linear plots at different potentials suggest the first order reaction kinetics toward oxygen. According to the $\mathrm{K}-\mathrm{L}$ equation,

Table 3 The Fe contents (in weight\%) of different samples from ICP-OES results

\begin{tabular}{|c|c|c|c|c|c|c|}
\hline $\begin{array}{l}\text { Amounts of } \mathrm{Fe} \\
(\mathrm{wt} \%)\end{array}$ & MIL-101(Fe) & MIL-0 DCD-800 & MIL-5 DCD-700 & MIL-5 DCD-800 & MIL-5 DCD-900 & MIL-5 DCD-1000 \\
\hline $\mathrm{Fe}$ & 17.49 & 70.20 & 28.92 & 46.55 & 38.97 & 19.56 \\
\hline
\end{tabular}



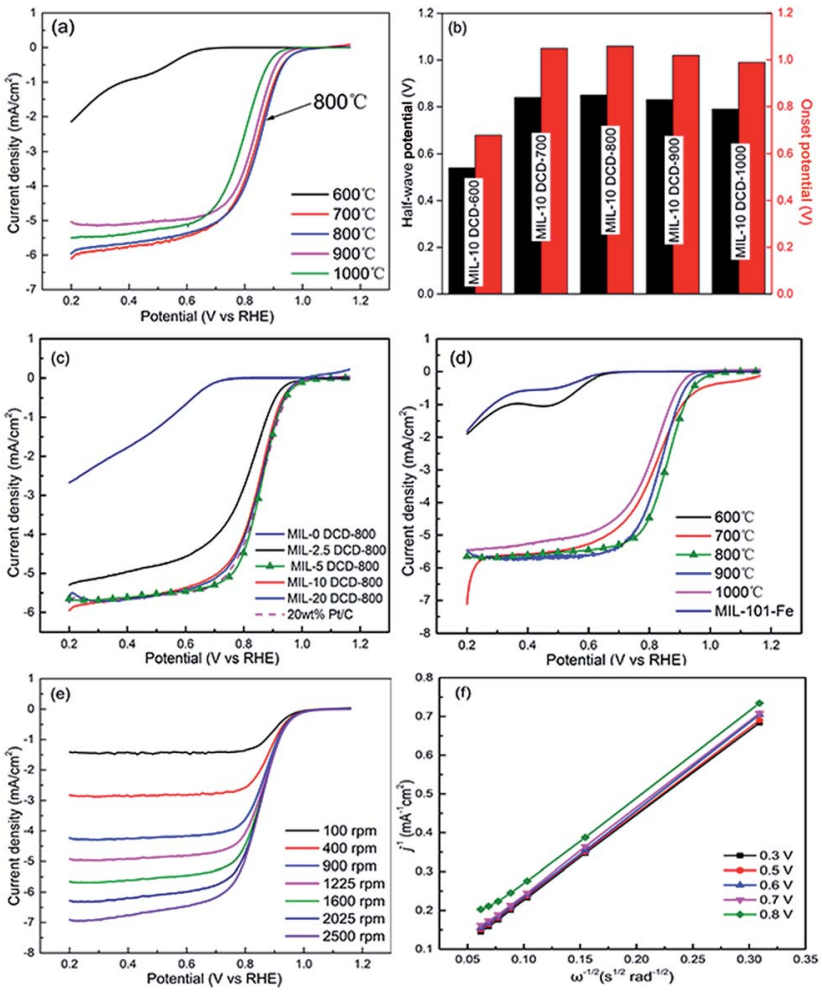

Fig. 7 RDE polarization curves in $\mathrm{O}_{2}$ saturated $0.1 \mathrm{M} \mathrm{KOH}$ of (a) MIL-10 DCD heat-treated at $600-1000^{\circ} \mathrm{C}$, (c) MIL- $x$ DCD-800 with different nitrogen dopants and $20 \mathrm{wt} \% \mathrm{Pt} / \mathrm{C}$, (d) MIL-5 DCD-600/700/800/ 900/1000 and MIL-101-Fe precursor, (e) MIL-5 DCD-800 at different rotating speed. (b) Comparison of the corresponding onset potentials and half-wave potentials measured on MIL-10 DCD heat-treated at $600-1000{ }^{\circ} \mathrm{C}$. (f) Koutecky-Levich plots at different potentials from $0.3 \mathrm{~V}$ to $0.8 \mathrm{~V}$.

the transferred electron number $(n)$ per oxygen molecule for MIL-5 DCD-800 is calculated to be approximately 3.93 over the potential range from 0.3 to $0.8 \mathrm{~V}$.

Fig. 8a illustrates the electron transfer number $(n)$ during ORR process and Fig. $8 \mathrm{~b}$ shows the hydrogen peroxide yield (\% $\mathrm{H}_{2} \mathrm{O}_{2}$ ) calculated from the RRDE results for MIL-5 DCD-800 and commercial Pt/C in alkaline solution. The $n$ number for MIL-5 DCD-800 is between 3.9 and 4.0, which is corresponding with the $n$ number calculated by K-L plot. It indicates that the ORR on MIL-5 DCD-800 was dominated by a 4 e process and $\% \mathrm{H}_{2} \mathrm{O}_{2}$ (or $\% \mathrm{HO}_{2}^{-}$) is below $1 \%$ for Pt/C and 3\% for MIL-5 DCD-800,
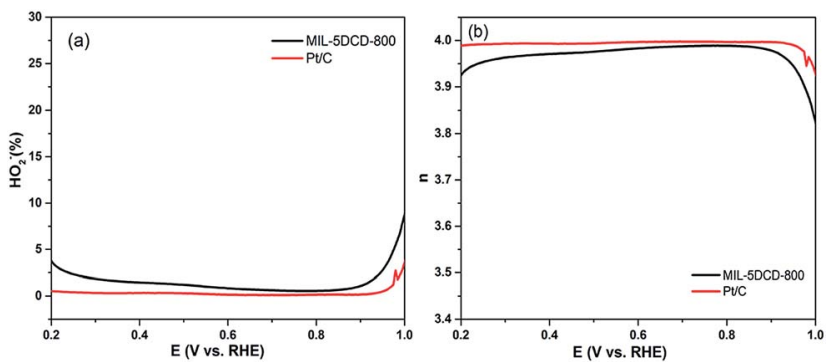

Fig. 8 (a) $\% \mathrm{H}_{2} \mathrm{O}_{2}$ and (b) electron-transfer number of MIL-5 DCD800 and commercial 20\% Pt/C during ORR process.
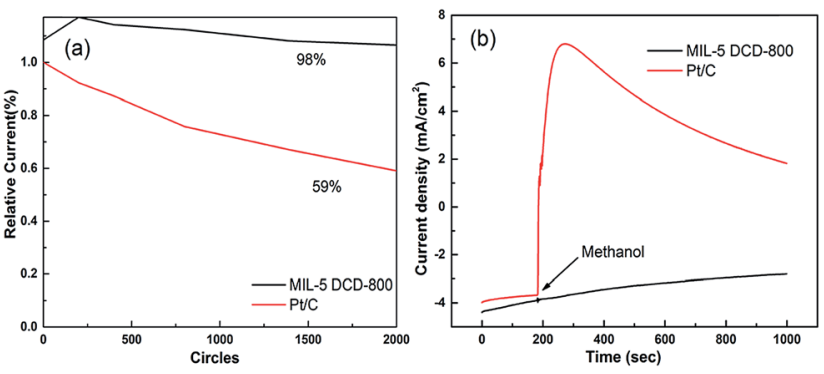

Fig. 9 (a) Stability evaluation of MIL-5 DCD-800 and JM 20\% Pt/C in $\mathrm{O}_{2}$-saturated $0.1 \mathrm{M} \mathrm{KOH}$; (b) chronoamperometric response of MIL-5 DCD -800 and JM 20\% Pt/C at $1600 \mathrm{rpm}$. The arrow indicates the introduction of 5 vol\% methanol.

respectively, which confirms that the 4 e reduction to water is predominated for both electrocatalysts in alkaline medium.

During accelerated durability test (ADT), CV curves and ORR polarization curves were collected in aqueous $\mathrm{KOH}$ solution at certain cycles to track the degradation of MIL-5 DCD-800 and commercial Pt/C.

\section{Methanol-tolerance and durability}

Fig. 9a shows the current density degradation of MIL-5 DCD-800 and commercial Pt/C after being cycled between 0.6 and $1.0 \mathrm{~V}$ for a total number of 2000 cycles in $\mathrm{O}_{2}$ saturated $\mathrm{KOH}(0.1 \mathrm{M})$ with a scan rate of $100 \mathrm{mV} \mathrm{s}^{-1}$. It is clear that $98 \%$ of the initial current density of MIL-5 DCD-800 toward ORR has been maintained, which is much better than that of the commercial Pt/C (59\%). It's probably attributable to the steady pyridinicand graphitic-N active sites and graphene which wrapped $\mathrm{Fe}$ nanoparticles protects the active metallic core from oxidation ${ }^{48}$ (Fig. 3a). While the deactivation of $\mathrm{Pt} / \mathrm{C}$ is mainly due to the dissolution of Pt nanoparticles active sites at high potentials, while this is not the case for non-precious metal electrocatalyst. More importantly, Fig. 9b shows that MIL-5 DCD-800 also exhibits a better methanol tolerance than commercial Pt/C. A sharp increase of the current density was observed for commercial Pt/C after the introduction of $5 \mathrm{vol} \%$ methanol into the alkaline solution, while the MIL-5 DCD- 800 was only slightly affected. It will be beneficial to further development of nitrogendoped carbon electrodes for many applications such as PEMFCs and direct methanol fuel cells (DMFCs).

\section{Conclusions}

In summary, we reported a simple and convenient approach for preparing nitrogen-doped mesoporous carbon materials. During pyrolysis process, the MOF compound was converted to carbon and nitrogen atoms were doped into the carbon products at the same time. We investigated systematically the physical structure character and electrocatalytic ability of different nitrogen dopant amount products and MIL precursor by various characterization methods. As a non-precious metal electrochemical catalyst, the synergistic effect of presence of pyridinic- and graphitic-N together with abundant graphene- 
wrapped Fe particles ${ }^{49,50}$ may promote the performance of the mesoporous carbon products for ORR, which is one of the most crucial factors to determine the performance of a fuel cell. These carbon products exhibit excellent oxygen reduction capability in alkaline medium.

\section{Acknowledgements}

This work is financially supported by the National Key Research and Development Program of China (No. 2016YFB0101208), the Key Program of National Natural Science Foundations of China (No. 21436003, No. 21306190, No. U1508202).

\section{Notes and references}

1 G. Wu, K. L. More, C. M. Johnston and P. Zelenay, Science, 2011, 332, 443-447.

2 W. L. Gu, L. Y. Hu, W. Hong, X. F. Jia, J. Li and E. K. Wang, Chem. Sci., 2016, 7, 4167-4173.

3 Q. G. He, Q. Li, S. Khene, X. M. Ren, F. E. Lopez-Suarez, D. Lozano-Castello, A. Bueno-Lopez and G. Wu, J. Phys. Chem. C, 2013, 117, 8697-8707.

4 S. C. Mu, X. Chen, R. H. Sun, X. B. Liu, H. Wu, D. P. He and K. Cheng, Carbon, 2016, 103, 449-456.

5 X. Tian, J. Luo, H. Nan, Z. Fu, J. Zeng and S. Liao, J. Mater. Chem. A, 2015, 3, 16801-16809.

6 A. Ishihara, S. Doi, S. Mitsushima and K.-i. Ota, Electrochim. Acta, 2008, 53, 5442-5450.

7 A. Ishihara, Y. Ohgi, K. Matsuzawa, S. Mitsushima and K.-i. Ota, Electrochim. Acta, 2010, 55, 8005-8012.

8 X. L. Wang, Y. J. Ke, H. Y. Pan, K. Ma, Q. Q. Xiao, D. Q. Yin, G. Wu and M. T. Swihart, ACS Catal., 2015, 5, 2534-2540.

9 W. Wei, H. Liang, K. Parvez, X. Zhuang, X. Feng and K. Muellen, Angew. Chem., Int. Ed., 2014, 53, 1570-1574.

10 D. Higgins, P. Zamani, A. P. Yu and Z. W. Chen, Energy Environ. Sci., 2016, 9, 357-390.

11 X. Y. Sun, J. Y. Xu, Y. X. Ding, B. S. Zhang, Z. B. Feng and D. S. Su, Chemsuschem, 2015, 8, 2872-2876.

12 R. Bashyam and P. Zelenay, Nature, 2006, 443, 63-66.

13 M. Lefevre, E. Proietti, F. Jaouen and J.-P. Dodelet, Science, 2009, 324, 71-74.

14 Z. Chen, D. Higgins, A. Yu, L. Zhang and J. Zhang, Energy Environ. Sci., 2011, 4, 3167-3192.

15 W.-J. Jiang, L. Gu, L. Li, Y. Zhang, X. Zhang, L.-J. Zhang, J.-Q. Wang, J.-S. Hu, Z. Wei and L.-J. Wan, J. Am. Chem. Soc., 2016, 138, 3570-3578.

16 W.-J. Jiang, J.-S. Hu, X. Zhang, Y. Jiang, B.-B. Yu, Z.-D. Wei and L.-J. Wan, J. Mater. Chem. A, 2014, 2, 10154-10160.

17 Y. Zhang, W.-J. Jiang, L. Guo, X. Zhang, J.-S. Hu, Z. Wei and L.-J. Wan, ACS Appl. Mater. Interfaces, 2015, 7, 11508-11515.

18 C. Mao, A. Kong, Y. Wang, X. Bu and P. Feng, Nanoscale, 2015, 7, 10817-10822.

19 H.-x. Zhong, J. Wang, Y.-w. Zhang, W.-l. Xu, W. Xing, D. Xu, Y.-f. Zhang and X.-b. Zhang, Angew. Chem., Int. Ed., 2014, 53, 14235-14239.

20 P. Zhang, F. Sun, Z. Xiang, Z. Shen, J. Yun and D. Cao, Energy Environ. Sci., 2014, 7, 442-450.
21 W. Xia, J. Zhu, W. Guo, L. An, D. Xia and R. Zou, J. Mater. Chem. A, 2014, 2, 11606.

22 X. Zhao, H. Zhao, T. Zhang, X. Yan, Y. Yuan, H. Zhang, H. Zhao, D. Zhang, G. Zhu and X. Yao, J. Mater. Chem. A, 2014, 2, 11666.

23 F. Yin, G. Li and H. Wang, Catal. Commun., 2014, 54, 17-21.

$24 \mathrm{X}$. He, F. Yin and G. Li, Int. J. Hydrogen Energy, 2015, 40, 9713-9722.

25 H. J. Zhang, Q. Z. Jiang, L. L. Sun, X. X. Yuan, Z. P. Shao and Z. F. Ma, Int. J. Hydrogen Energy, 2010, 35, 8295-8302.

26 T. Liu, P. P. Zhao, X. Hua, W. Luo, S. L. Chen and G. Z. Cheng, J. Mater. Chem. A, 2016, 4, 11357-11364.

27 X. J. Wang, H. G. Zhang, H. H. Lin, S. Gupta, C. Wang, Z. X. Tao, H. Fu, T. Wang, J. Zheng, G. Wu and X. G. Li, Nano Energy, 2016, 25, 110-119.

28 H. Sun, H. X. Su, X. Y. Ma, P. F. Zhang, X. Zhang, X. P. Dai, J. S. Gao, C. Chen and S. G. Sun, Electrochim. Acta, 2016, 205, 53-61.

29 D. Riou, O. Roubeau and G. Ferey, Microporous Mesoporous Mater., 1998, 23, 23-31.

30 K. M. L. Taylor-Pashow, J. Della Rocca, Z. Xie, S. Tran and W. Lin, J. Am. Chem. Soc., 2009, 131, 14261-14263.

31 K. Parvez, S. Yang, Y. Hernandez, A. Winter, A. Turchanin, X. Feng and K. Muellen, ACS Nano, 2012, 6, 9541-9550.

32 J. Shin, M. Kim, J. Cirera, S. Chen, G. J. Halder, T. A. Yersak, F. Paesani, S. M. Cohen and Y. S. Meng, J. Mater. Chem. A, 2015, 3, 4738-4744.

33 J. Tang, M. Yang, M. Yang, J. Wang, W. Dong and G. Wang, New J. Chem., 2015, 39, 4919-4923.

34 S. J. You, X. B. Gong, W. Wang, D. P. Qi, X. H. Wang, X. D. Chen and N. Q. Ren, Adv. Energy Mater., 2016, 6, 1501497.

35 L. Shang, H. Yu, X. Huang, T. Bian, R. Shi, Y. Zhao, G. I. N. Waterhouse, L.-Z. Wu, C.-H. Tung and T. Zhang, Adv. Mater., 2016, 28, 1668-1674.

36 C. V. Rao, C. R. Cabrera and Y. Ishikawa, J. Phys. Chem. Lett., 2010, 1, 2622-2627.

37 K. Y. Park, J. H. Jang, J. E. Hong and Y. U. Kwon, J. Phys. Chem. C, 2012, 116, 16848-16853.

38 H. B. Li, W. J. Kang, L. Wang, Q. L. Yue, S. L. Xu, H. S. Wang and J. F. Liu, Carbon, 2013, 54, 249-257.

39 C. Jeyabharathia, P. Venkateshkumarb, M. S. Raoa, J. Mathiyarasua and K. L. N. Phania, Electrochim. Acta, 2012, 74, 171-175.

40 L. Y. Feng, Y. Y. Yan, Y. G. Chen and L. J. Wang, Energy Environ. Sci., 2011, 4, 1892-1899.

41 D. Guo, R. Shibuya, C. Akiba, S. Saji, T. Kondo and J. Nakamura, Science, 2016, 351, 361-365.

42 Z. Yang, H. Nie, X. a. Chen, X. Chen and S. Huang, J. Power Sources, 2013, 236, 238-249.

43 H. Kim, K. Lee, S. I. Woo and Y. Jung, Phys. Chem. Chem. Phys., 2011, 13, 17505-17510.

44 L. Lai, J. R. Potts, D. Zhan, L. Wang, C. K. Poh, C. Tang, H. Gong, Z. Shen, J. Lin and R. S. Ruoff, Energy Environ. Sci., 2012, 5, 7936-7942.

45 V. M. Dhavale, S. K. Singh, A. Nadeema, S. S. Gaikwad and S. Kurungot, Nanoscale, 2015, 7, 20117-20125. 
46 P. P. Su, H. Xiao, J. Zhao, Y. Yao, Z. G. Shao, C. Li and Q. H. Yang, Chem. Sci., 2013, 4, 2941-2946.

47 Y. C. Wang, Y. J. Lai, L. Song, Z. Y. Zhou, J. G. Liu, Q. Wang, X. D. Yang, C. Chen, W. Shi, Y. P. Zheng, M. Rauf and S. G. Sun, Angew. Chem., 2015, 54, 9907-9910.

48 M. Tavakkoli, T. Kallio, O. Reynaud, A. G. Nasibulin, C. Johans, J. Sainio, H. Jiang, E. I. Kauppinen and K. Laasonen, Angew. Chem., Int. Ed., 2015, 54, 4535-4538.
49 J. Y. Li, J. Wang, D. F. Gao, X. Y. Li, S. Miao, G. X. Wang and X. H. Bao, Catal. Sci. Technol., 2016, 6, 2949-2954.

50 J. A. Varnell, E. C. M. Tse, C. E. Schulz, T. T. Fister, R. T. Haasch, J. Timoshenko, A. I. Frenkel and A. A. Gewirth, Nat. Commun., 2016, 7, 12582. 